Article

\title{
Antibacterial Activity of Shikimic Acid from Pine Needles of Cedrus deodara against Staphylococcus aureus through Damage to Cell Membrane
}

\author{
Jinrong Bai ${ }^{1}$, Yanping $\mathrm{Wu}^{1}{ }^{1}$, Xiaoyan Liu ${ }^{1}$, Kai Zhong ${ }^{1, *}$, Yina Huang ${ }^{2}$ and Hong Gao ${ }^{1, *}$ \\ Received: 7 September 2015 ; Accepted: 3 November 2015 ; Published: 13 November 2015 \\ Academic Editor: Sanjay K. Srivastava \\ 1 Department of Food Science and Technology, College of Light Industry, Textile and Food Engineering, \\ Sichuan University, Chengdu 610065, China; baijinrong01@hotmail.com (J.B.); wyp9202@163.com (Y.W.); \\ 1xy19831231@163.com (X.L.) \\ 2 Department of Public Health, West China Medical School, Sichuan University, Chengdu 610041, China; \\ dir0932@sina.com \\ * Correspondence: eric211@163.com (K.Z.); gao523@hotmail.com (H.G.); \\ Tel.: +86-28-8540-5236 (K.Z. \& H.G.); Fax: +86-28-8540-5137 (K.Z. \& H.G.)
}

\begin{abstract}
Shikimic acid (SA) has been reported to possess antibacterial activity against Staphylococcus aureus, whereas the mode of action of SA is still elusive. In this study, the antibacterial activity and mechanism of SA toward S. aureus by cell membrane damage was investigated. After SA treatment, massive $\mathrm{K}^{+}$and nucleotide leakage from $S$. aureus, and a significant change in the membrane potential was observed, suggesting SA may act on the membrane by destroying the cell membrane permeability. Through transmission electron microscopic observations we further confirmed that SA can disrupt the cell membrane and membrane integrity. Meanwhile, SA was found to be capable of reducing the membrane fluidity of the S. aureus cell. Moreover, the fluorescence experiments indicated that SA could quench fluorescence of Phe residues of the membrane proteins, thus demonstrating that $S A$ can bind to $S$. aureus membrane proteins. Therefore, these results showed the antibacterial activity of SA against $S$. aureus could be caused by the interactions of SA with $S$. aureus membrane proteins and lipids, resulting in causing cell membrane dysfunction and bacterial damage or even death. This study reveals the potential use of SA as an antibacterial agent.
\end{abstract}

Keywords: shikimic acid; antibacterial activity; Staphylococcus aureus; membrane damage; membrane proteins; membrane lipids

\section{Introduction}

Severe foodborne disease and intoxications are a widespread and growing public health problem [1]. Nowadays, this problem has caused more attentions of governments and food industry than a few decades ago. Foodborne disease is one of the major causes of illness and death, and about 48 million cases of foodborne diseases are estimated to occur each year in the United States [2,3]. Among them, staphylococcal foodborne disease is a common and major foodborne disease worldwide [4]. Staphylococcus aureus is a significant pathogen for foodborne disease, and caused many people illness and death every year [3]. S. aureus can cause a series of illnesses from mild skin infections to more severe life-threatening diseases, such as osteomyelitis, pneumonia, and septicemia [5]. One of the most common toxins in foodborne intoxication is staphylococcal 
enterotoxins, which can cause intense diarrhea, nausea, vomiting, and abdominal pain [6]. Therefore, the control of this pathogen is a major concern for people and food industry.

Some conventional physical treatments, including thermal inactivation, irradiation, chained cold treatment, and high-sugar or -salt treatments, have been applied to control S. aureus. However, some physical treatments may cause adverse effects on the food such as color change, browning, reductions of aroma nutrients and functional substances, and others [7]. In addition to physical treatments, chemical preservatives are also used in the food industry to control foodborne pathogens and to extend food shelf-lives [8]. While chemical preservatives are convenient for use, their safety and potential health issues have been a controversial topic. Further, indiscriminate use of antibiotics contributed to inducing antibiotic-resistant pathogens. Therefore, there is an enhanced tendency to use safe and efficient natural antimicrobials for the control of foodborne pathogens.

Shikimic acid (SA) is an important organic acid not only as a key intermediate in the biosynthesis of aromatic compounds, but also as a starting material in the chemical synthesis of useful compounds. With the sudden outbreak of flu, SA has aroused unprecedented attention as a key material in the synthesis of antiviral drug Tamiflu ${ }^{\circledR}$, which is effective in antiviral infections such as bird flu and swine flu [9]. The occurrence of SA spreads widely in plants, and extremely abundant in Chinese star anise [10]. In the biological studies, SA has been reported to have anti-inflammatory, analgesia, antioxidant, antithrombotic, and antibacterial activities [11-14]. In a previous study, we found SA as a major antibacterial compound against $S$. aureus in the water extract obtained from pine needles of Cedrus deodara [15].

So far, SA has been extensively studied and applied, but few literatures have reported its antibacterial mechanism against $S$. aureus specifically. In order to fully understand the mode of action and for the further application of SA, the antibacterial mechanism of SA against S. aureus was explored. Importantly, it is the first time to elucidate the mode of action of SA against S. aureus by investigating the cell membrane permeability, membrane potential, membrane integrity, cell morphology, membrane fluidity, and membrane protein.

\section{Results and Discussion}

\subsection{Antibacterial Activity of Shikimic Acid (SA) to Staphylococcus aureus (S. aureus)}

Minimal inhibition concentration (MIC) of SA against S. aureus American type culture collection (ATCC) 6538 was determined to be $2.5 \mathrm{mg} / \mathrm{mL}$.

\subsection{Leakage of Cell Constituents Induced by SA}

To demonstrate the effect of SA on the membrane permeability, the amount of $\mathrm{K}^{+}$efflux and nucleotide leakage from S. aureus were measured. After SA treatment, the release of $\mathrm{K}^{+}$and nucleotide from S. aureus cells increased immediately and significantly, and $\mathrm{K}^{+}$efflux and nucleotide leakage almost remained constant after $10 \mathrm{~min}$ of incubation (Figure 1). Moreover, with the increase of SA concentration, the amounts of $\mathrm{K}^{+}$efflux and nucleotide leakage increased correspondingly. Accordingly, SA induced a rapid $\mathrm{K}^{+}$and nucleotide release from $S$. aureus, reaching the maximal efflux after only $10 \mathrm{~min}$ treatment. The result shows that SA probably has an ability to influence the membrane permeability. When membrane permeability changes and membrane becomes damaged, some ions, nucleotides, and proteins could leak out. Hence, SA may have destroyed the S. aureus $\mathrm{K}^{+}$ channels, leading to the massive effluxes of $\mathrm{K}^{+}$from S. aureus. Additionally, SA rapidly increased membrane permeability and damaged the membrane, which revealed that SA possessed a rapid and direct antibacterial effect against $S$. aureus. Many other antibacterial agents exhibited similar actions on different bacteria. It is reported that peptides from barbel protein hydrolysates show the ability to disturb the cell membrane and to cause releasing $\mathrm{K}^{+}$extracellularly [16]. Chlorogenic acid was reported to induce an immediate and massive efflux of $\mathrm{K}^{+}$and nucleotides from $S$. dysenteriae and S. pneumoniae by increasing plasma membrane permeabilization [17]. These findings support our 
results and speculation that SA probably acts on the membrane and increases the permeability of cell membranes.
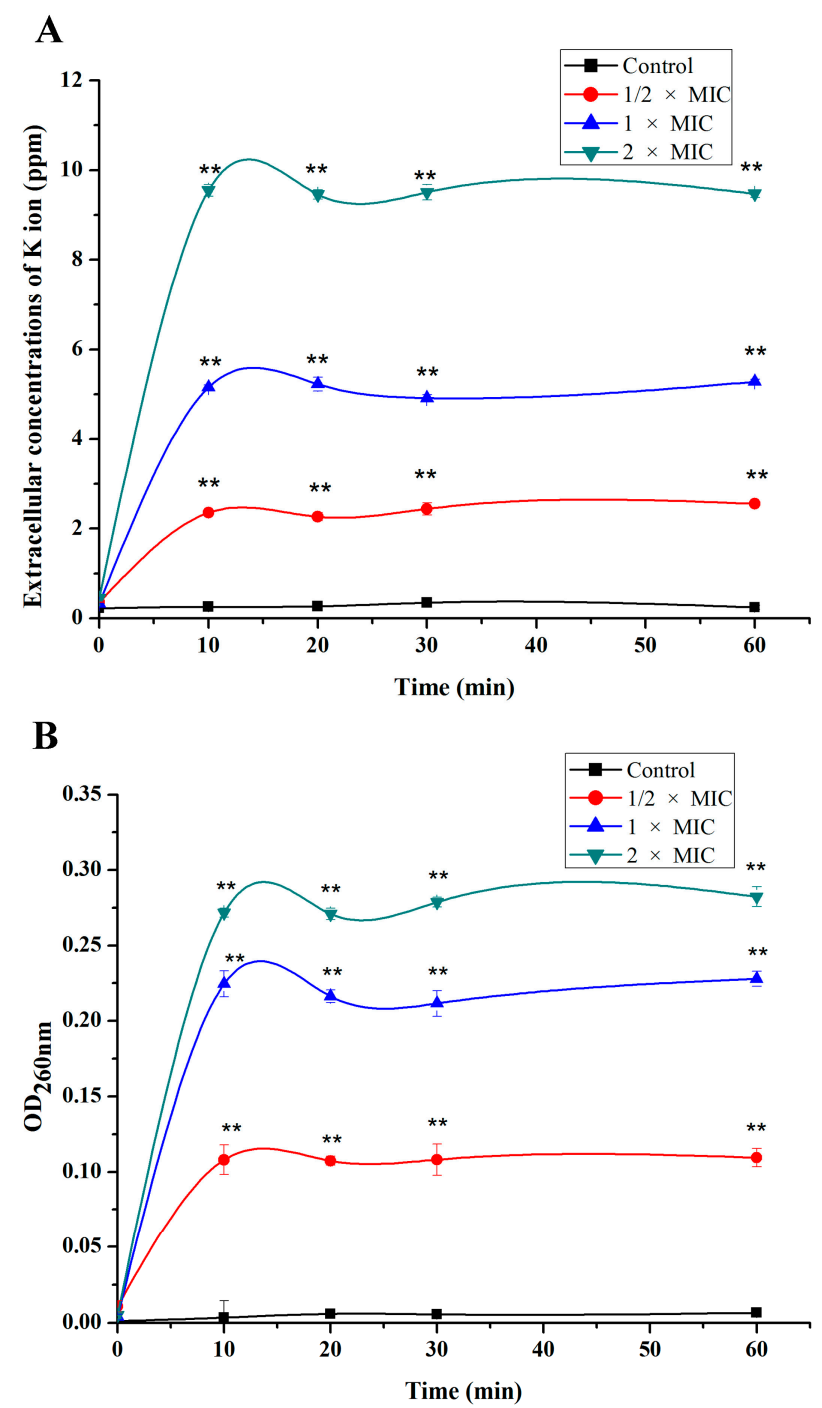

Figure 1. Effect of shikimic acid on the amounts of $\mathrm{K}^{+}(\mathbf{A})$ and the cell nucleotide (B) leakage from S. aureus American type culture collection (ATCC) 6538. Data are expressed as mean \pm standard deviation. ${ }^{* *} p<0.01$, compared with control. Minimal inhibition concentration (MIC) is defined to be the lowest concentration of shikimic acid (SA) capable of inhibiting the tested bacterial visible growth.

\subsection{Effect of $S A$ on Membrane Potential}

The changes of membrane potential were monitored to study the mode of action of SA. DiBAC4(3), a kind of fluorescent probe, is used for monitoring the changes of membrane potential. When membrane becomes depolarized, the dye crosses the cell membrane and fluorescence enhances. Conversely, fluorescence decrease in the state of membrane hyperpolarization [18]. As shown in Figure 2, fluorescence decreased when S. aureus cells were treated with SA in a dose-dependent manner. So, the result implied that SA hyperpolarized cell membrane of $S$. aureus and changed the cell membrane permeability. A previous study has indicated that chlorogenic acid may affect the $S$. aureus cell membrane structure and cause the cell membrane hyperpolarization [19]. It is also reported that chlorogenic acid has been reported to disrupt the cell membrane and then depolarize the bacterial cell membrane of S. pneumonia and S. dysenteriae [20]. Although some discrepancy is noticed between the previous two reports describing the effects of chlorogenic acid on cell membrane polarization, 
antibacterial agents showed effects on cell membrane by changing its polarization. Combining the above results on $\mathrm{K}^{+}$efflux with our observation that $\mathrm{K}^{+}$was released from $S$. aureus cell by $\mathrm{SA}$ in a dose-responding manner, we suggest that $\mathrm{SA}$ induces the hyperpolarization of cell membrane. Hence, it was suggested that SA may have an ability to change the membrane potential of S. aureus.

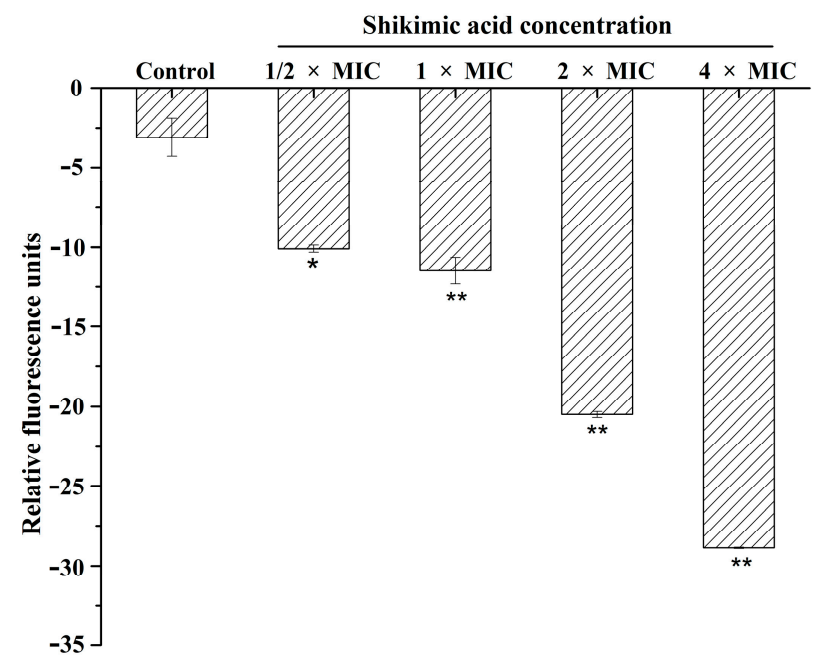

Figure 2. Effect of shikimic acid on the membrane potential of S. aureus ATCC 6538. Data are expressed as mean \pm standard deviation. ${ }^{*} p<0.05,{ }^{* *} p<0.01$, compared with control.

\subsection{Membrane Integrity}

To further characterize the antibacterial action of SA on the S. aureus membrane integrity, flow cytometric analysis was performed with LIVE/DEAD BacLight bacterial viability kit. The kit is composed of two kinds of nucleic acid dyes: green fluorescent SYTO 9 is able to penetrate all bacterial membrane, red fluorescent propidium iodide (PI) only enters into cells with damaged membrane [21]. Due to the strong fluorescence signal of SYTO 9 in $600 \mathrm{~nm}$ except for $525 \mathrm{~nm}$, it overlaps with the fluorescence signal of PI in $620 \mathrm{~nm}$. Therefore, the cloud of untreated samples of S. aureus is in the upper right quadrant. [22]. Additionally, when the cell membrane is damaged, PI enters into the cell and produces red fluorescence, which caused intensity of SYTO 9 fluorescence to become lower. Due to fluorescence resonance energy transfer, the intensity of red fluorescence becomes lower, since green fluorescence is in lower intensity [23]. To analyze cell membrane integrity, the flow cytometry analyses were performed in two regions: R1 (membrane damaged and dead cells region), and R2 (viable cells region).

Following $3 \mathrm{~h}$ incubation with $1 \times$ MIC of SA, the population of cells with intact membrane was $53.6 \%$ (Figure 3B), whereas that was $93.19 \%$ for the untreated sample (Figure $3 \mathrm{~A}$ ). The population of cells with damaged membrane increased $6.81 \%$ in the untreated sample to $46.4 \%$ with $1 \times$ MIC of SA treatment, indicating that cell membrane integrity was lost after exposure to SA. Significantly, there were two fluorescent populations in R1 region. One population (Figure 3B, black arrow) had higher intensity in both red and green fluorescence than the other population had (Figure 3B, white arrow). This pattern likely occurs because the cells were stained by different concentrations of SYTO 9 and PI, resulting from the short of nucleic acids in the second population cells [23]. Overall, the above results further revealed that the cell membrane was the target of SA in its antibacterial action.

\subsection{Transmission Electron Microscopy (TEM)}

To visually disclose the action of SA on cell membrane, the effect of SA on S. aureus morphology and the membrane was observed by TEM. Compared with untreated S. aureus cells, the cellular morphology of $S$. aureus treated with SA changed significantly. The untreated S. aureus cells maintained plump, globose, and integrity, and the S. aureus wall and membrane were intact, 
appearing as well-defined cell membranes. Moreover, normal cells showed homogeneous electron density (Figure 4A). In contrast, the S. aureus cells treated with SA showed distorted shape and lost the clear boundary of cell membrane. The cell membrane permeability changed, or may even been damaged, leading to the leakage of cell contents into the media, resulting in electron translucence of the cell (Figure 4B). It was easy to find cell debris and electron-dense particles around the disrupted cells, which was likely due to the damaged and lysed bacteria. Additionally, probably because of cytoplasmic disruption, the cells treated with SA showed electron density heterogeneity (Figure 4C). Cell walls and membranes can maintain cell morphology and control normal cellular functions. Through TEM observations of the S. aureus cells, we further verified that SA can disrupt the cell membrane, including cell permeability and cell integrity, which probably causes cell growth inhibition and death.

A

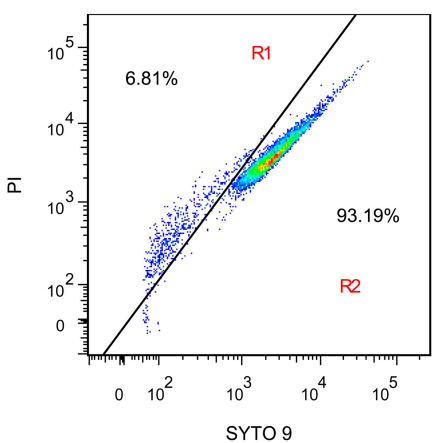

B

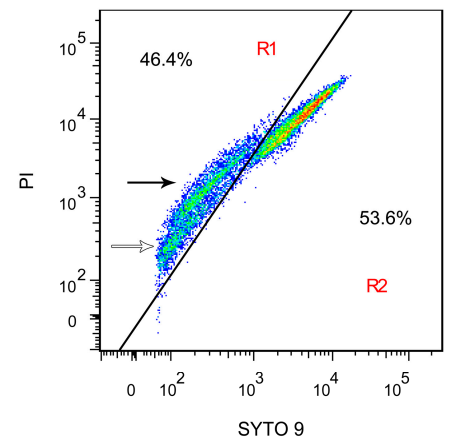

$c$

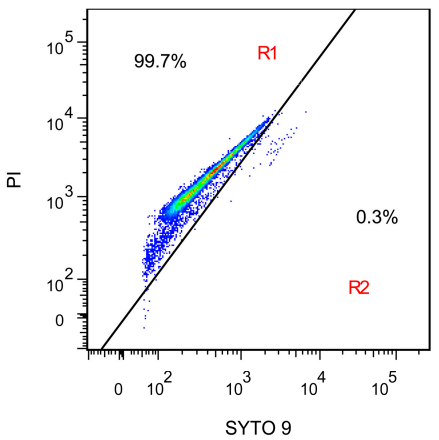

Figure 3. Flow cytometric analysis of S. aureus ATCC 6538 stained by SYTO 9 and propidium iodide (PI). (A) untreated; (B) treated with shikimic acid at $1 \times \mathrm{MIC}$ for $3 \mathrm{~h}$; and (C) positive control, treated with $70 \%$ isopropanol for $3 \mathrm{~h}$. R1, membrane disrupted cells gate; R2, viable cells gate. Two fluorescent populations are observed in R1 with a higher fluorescent intensity (black arrow) and lower fluorescent intensity (white arrow). The red, green, and blue colors represent the decrement of cell density.

A

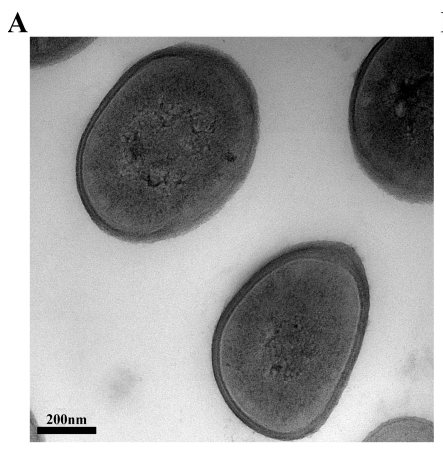

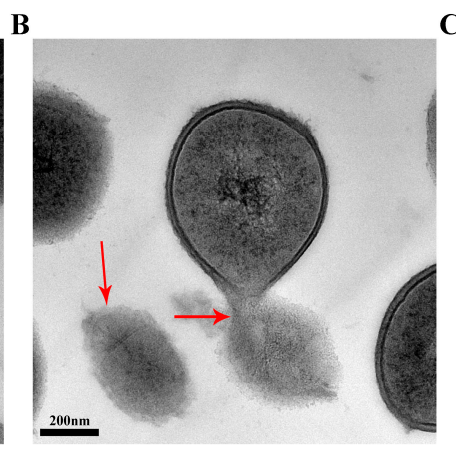

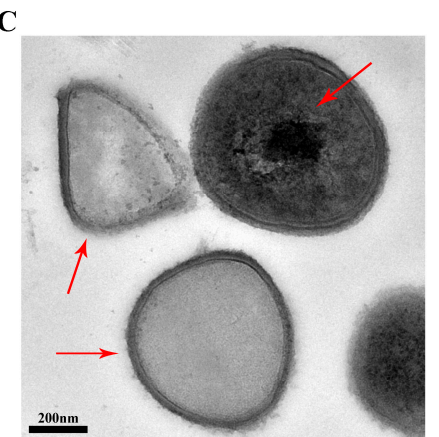

Figure 4. Transmission electron micrographs of S. aureus ATCC 6538 cells. (A) untreated bacteria; and $(B, C)$ bacteria treated with shikimic acid at $1 \times$ MIC for $12 \mathrm{~h}$.

\subsection{Effect of $S A$ on the S. aureus Cell Membrane Fluidity}

To further assess the mechanism of SA on the S. aureus membrane, we measured the fluorescence polarization of DPH to test the cells' membrane fluidity. Polarization values could reflect the changes in membrane fluidity. The DPH is a kind of hydrophobic and non-fluorescent probe, which can bind to the cell membrane lipophilic tails and emit strong fluorescence when the cell membrane is intact $[24,25]$. The higher fluorescence polarization indicates the lower membrane fluidity. As shown in Figure 5, fluorescence polarization values increased with the concentration of SA from $1 / 8 \times$ MIC to $1 / 2 \times$ MIC, suggesting a reduction of membrane fluidity. So, SA was capable of affecting the fluidity of hydrophobic membrane interface of the $S$. aureus cell. Membrane fluidity 
has many important functions, such as transferring signals, energy transformation, and nutrient transportation, which are closely related to membrane fluidity. Hence, membrane fluidity stability performs a significant role to maintain the normal function of cell [26]. The above results indicated that SA may damage the structure of cell membrane lipid bilayers and hinder the cell modulation of the membrane composition, resulting in a decrease of membrane fluidity, increase of cell permeability, and partial solubility of the membrane.

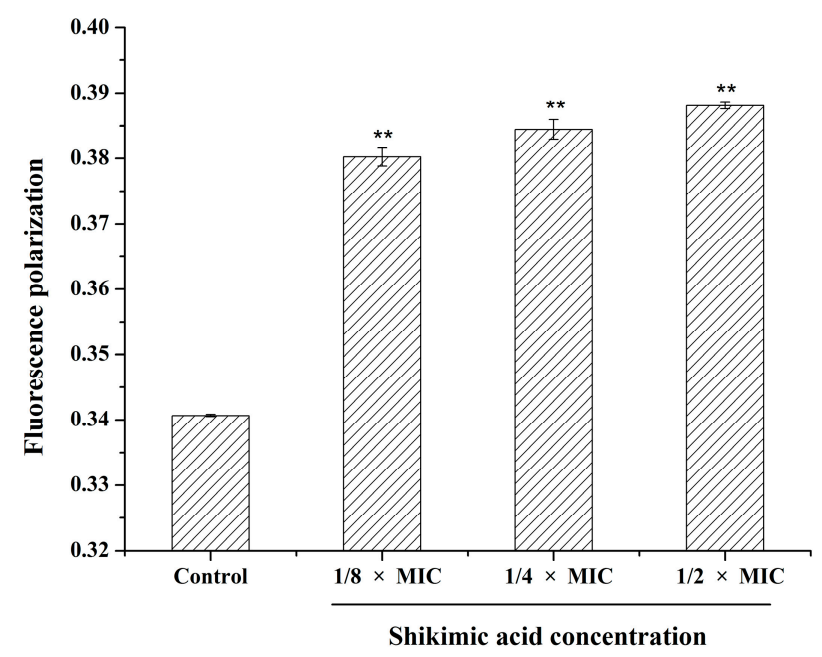

Figure 5. Effect of shikimic acid on the fluidity of membrane lipid of S. aureus ATCC 6538. Data are expressed as mean \pm standard deviation. ${ }^{* *} p<0.01$, compared with control.

\subsection{Effect of $S A$ on the S. aureus Cell Membrane Protein}

Cell membrane exhibits fluorescence due to tryptophan (Trp), tyrosine (Tyr) and phenylalanine (Phe) residues. Some amino acid residues are situated inside or in the crevice of cell membrane proteins, while some amino acid residues are situated on the cell membrane protein surface [27]. KI is widely used to examine the location of amino acid residues. $\mathrm{I}^{-}$can directly bind to the amino acid residues that locate on the surface of cell membrane protein, and emission fluorescence will be decreased and quenched. On the other hand, $\mathrm{I}^{-}$cannot directly bind to the amino acid residues that are located inside or in the crevice of cell membrane proteins, and fluorescence spectra will not be affected [27]. Figure 6A,B showed the effect of KI on fluorescence intensity of Tyr and Phe residues at $\lambda_{\text {ex }} 258 \mathrm{~nm}$ and $\lambda_{\text {ex }} 296 \mathrm{~nm}$, respectively. Fluorescence intensity of Phe residues decreased dramatically because $\mathrm{I}^{-}$could bind to Phe residues partly, which suggested that some of the Phe residues situated on the $S$. aureus cell membrane surface. However, with the increased of concentration of KI, fluorescence spectra of Tyr residues had no change, which suggested that Tyr residues primarily situated $S$. aureus cell membrane inside or in the crevice. Since the excitation peak of Trp residues is close to the excitation peak of Tyr, the effect of quenching agent on the fluorescence of Trp was similar to that of Tyr. Therefore, the change of Phe residue fluorescence intensity was detected to test whether SA interacts with the cell membrane protein or not.

When S. aureus cells are exposed to antibacterial agents, the cell membrane protein conformation changed, and the emission fluorescence of Phe residues would be decreased and quenched. Moreover, the Phe residues would be exposed from inside of membrane proteins, which led to the changes of emission fluorescence intensity and fluorescence spectra. Therefore, fluorescence intensity of Phe residues was selected to reflect whether SA interacts with cell membrane protein [28]. With the concentration of SA ranging from $1 / 4 \times$ MIC to $2 \times$ MIC, the Phe residues emission fluorescence intensity decreased correspondingly, and even close to zero (Figure 6C). The result demonstrated that SA may make the Phe residues situated in the crevice or inside of the cell membrane protein exposed outside of the membrane protein. In addition to the decrement of fluorescence intensity, when the 
concentration of SA was set at $1 \times$ MIC or $2 \times$ MIC, the emission fluorescence spectra of Phe residues significantly changed as compared to the control. The above results indicated that SA could quench fluorescence of Phe residues and change the conformation and structure of cell membrane protein. In this regard, the antibacterial action of SA may be mainly due to destruction of the cell membrane proteins, which influenced the normal function of the cell membrane and resulted in bacterial damage or even death. Hence, it was implied that membrane proteins would be the target molecules on the cell surface for the action of SA against of S. aureus.
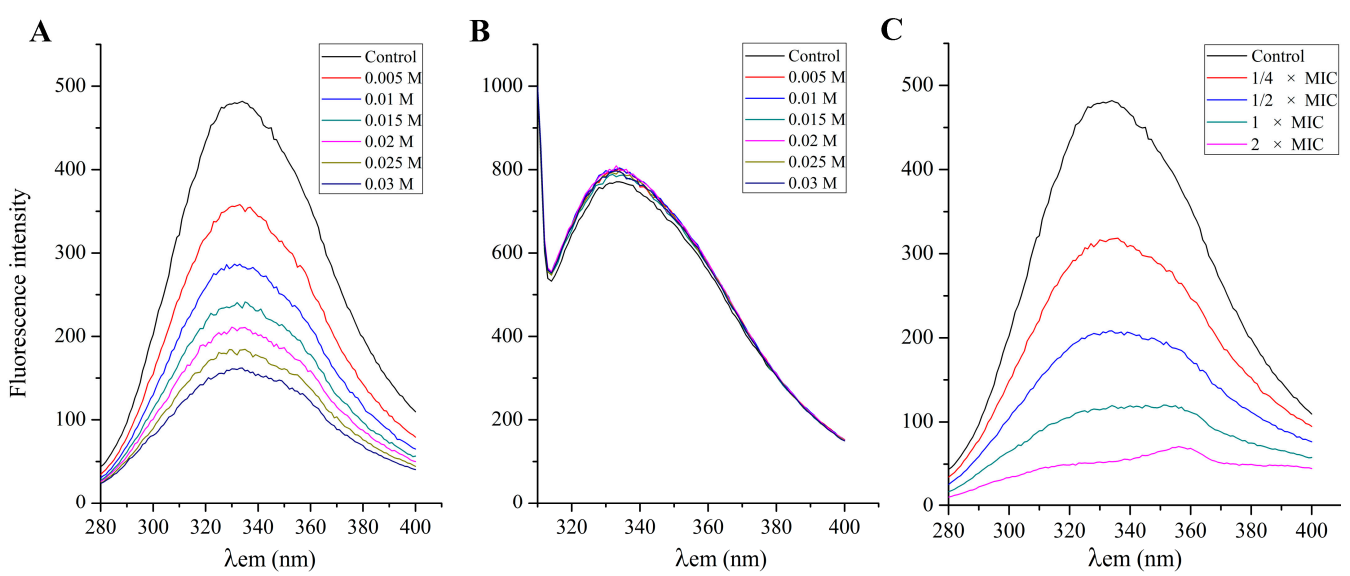

Figure 6. Effect of KI on fluorescence intensity of the S. aureus ATCC 6538 membrane protein at $\lambda_{\mathrm{ex}}$ $258 \mathrm{~nm}$ (A) and $\lambda_{\mathrm{ex}} 296 \mathrm{~nm}$ (B); effect of shikimic acid on fluorescence intensity of the S. aureus ATCC 6538 membrane protein at $\lambda_{\text {ex }} 258 \mathrm{~nm}$ (C). Concentrations of KI (from the top down) were 0.005, 0.01, $0.015,0.02,0.025$ and $0.03 \mathrm{M}$, respectively. Concentrations of shikimic acid (from the top down) were $1 / 4 \times$ MIC, $1 / 2 \times$ MIC, $1 \times$ MIC and $2 \times$ MIC, respectively.

\section{Materials and Methods}

\subsection{Materials}

SA was obtained from $C$. deodara pine needles according to the previous report [15], and prepared in solutions with distilled water for use in all experiments. All other chemicals were of analytical grade.

\subsection{Assay for Antibacterial Activity}

The strain S. aureus ATCC 6538 was purchased from the China Medical Culture Collection Center (Beijing, China). S. aureus was inoculated in nutrition broth (NB) containing $1 \%$ tryptone, $0.3 \%$ beef extract, and $0.5 \% \mathrm{NaCl}$. The antibacterial activity assay was performed using the method of microdilution broth with minor modifications [19]. Briefly, logarithmic phase S. aureus cells were diluted with fresh medium to a density of $1 \times 10^{6} \mathrm{CFU} / \mathrm{mL}$. Bacterial suspensions $(100 \mu \mathrm{L})$ and of SA $(100 \mu \mathrm{L})$ were gently added into the 96 -well plates, then the bacterial suspensions were incubated at $37^{\circ} \mathrm{C}$ for $12 \mathrm{~h}$. The final concentration of SA was in range from 0.625 to $10 \mathrm{mg} / \mathrm{mL}$. Minimal inhibition concentration (MIC) is defined to be the lowest concentration of SA capable of inhibiting the tested bacterial visible growth.

\subsection{Measurement of the Potassium Efflux}

The assay of the potassium efflux was performed following the reported procedure [29] with a few modifications. In brief, the logarithmic phase $S$. aureus cells was collected by centrifugation at $5000 \times g$ for $5 \mathrm{~min}$ at $4{ }^{\circ} \mathrm{C}$, washed twice, and re-suspended to make $1 \times 10^{6} \mathrm{CFU} / \mathrm{mL}$ in $0.85 \%$ saline solution. Then, $20 \mathrm{~mL}$ of the suspensions were incubated with three concentrations of SA $(1 / 2 \times \mathrm{MIC}$, $1 \times \mathrm{MIC}, 2 \times \mathrm{MIC})$ at $37^{\circ} \mathrm{C}$ for different times. Sampling was performed at $0,10,20,30$, and $60 \mathrm{~min}$ 
after the start of incubation, and the solutions were filtered through a $0.22 \mu \mathrm{m}$ filter membrane. The concentration of released $\mathrm{K}^{+}$was measured using an atomic absorption spectrometer (PinAAcle 900, PerkinElmer, Waltham, MA, USA).

\subsection{Measurement of the Nucleotide Leakage}

The nucleotide leakage from S. aureus was determined following the reported method [30] with a slight modification. Logarithmic phase $S$. aureus cells were collected by centrifugation at $5000 \times g$ for $5 \mathrm{~min}$ at $4{ }^{\circ} \mathrm{C}$, washed twice, and re-suspended to make $1 \times 10^{6} \mathrm{CFU} / \mathrm{mL}$ in $0.85 \%$ saline solution. Then, $20 \mathrm{~mL}$ of the suspensions were incubated with three concentrations of SA $(1 / 2 \times \mathrm{MIC}, 1 \times \mathrm{MIC}$, $2 \times \mathrm{MIC})$ at $37^{\circ} \mathrm{C}$ for different time. Sampling was performed at $0,10,20,30$, and $60 \mathrm{~min}$ after the start of incubation, and the solutions were filtered through a $0.22 \mu \mathrm{m}$ filter membrane. The filtrates were measured by a microplate reader (SpectraMax 190, Molecular Devices, Sunnyvale, CA, USA) at $260 \mathrm{~nm}$.

\subsection{Membrane Potential Assay}

The membrane potential assay was carried out using the reported method with a few modifications [31]. Briefly, Logarithmic phase S. aureus cells were diluted with fresh medium to a density of $1 \times 10^{7} \mathrm{CFU} / \mathrm{mL}$. Three milliliters of suspensions were incubated with four different concentrations of SA $(1 / 2 \times \mathrm{MIC}, 1 \times \mathrm{MIC}, 2 \times \mathrm{MIC}, 4 \times \mathrm{MIC})$ at room temperature for $10 \mathrm{~min}$. An amount of $0.5 \mu \mathrm{g} / \mathrm{mL}$ of bis-(1,3-dibutylbarbituric acid) trimethine oxonol (DiBAC4(3); Life Technologies, Eugene, OR, USA), was then added and incubated for $5 \mathrm{~min}$. The fluorescence was measured using a fluorescence spectrophotometer (G9800A, Agilent, Santa Clara, CA, USA). The excitation was set at $492 \mathrm{~nm}$ and emission was set at $515 \mathrm{~nm}$.

\subsection{Membrane Integrity}

The effect of SA on S. aureus membrane integrity was determined using flow cytometry according to the reported method with slight modifications [21]. The LIVE/DEAD BacLight bacterial viability kit (Life Technologies, Eugene, OR, USA) contains two stains, component A (SYTO 9 dye, $3.34 \mathrm{mM}$ ) and component B (Propidium iodide, $20 \mathrm{mM}$ ). Equal volumes of two stains were mixed and stored at $-25^{\circ} \mathrm{C}$ until use. Logarithmic phase $S$. aureus cells were washed twice, and re-suspended at a final density of $1 \times 10^{9} \mathrm{CFU} / \mathrm{mL}$ in $0.85 \%$ saline solution. Then, $20 \mathrm{~mL}$ of suspensions were incubated with $1 \times$ MIC of SA at $37^{\circ} \mathrm{C}$. After three hours, the cells were washed twice and re-suspended at a final density of $1 \times 10^{6} \mathrm{CFU} / \mathrm{mL}$ in $0.85 \%$ saline solution. An amount of $1 \mathrm{~mL}$ of cell suspension was stained with $3 \mu \mathrm{L}$ of the dye mixture. Subsequently, the samples were incubated in the dark for $15 \mathrm{~min}$ at room temperature. The proportions of live and death cells were analyzed by a flow cytometer (FACSVerse, Becton Dickinson, Franklin Lakes, NJ, USA). The green fluorescent SYTO 9 were examined using a $525 \mathrm{~nm}$ channel, and the red fluorescent PI were examined using a $620 \mathrm{~nm}$ channel. The experiment collected 50,000 cell events with a low flow rate. The suspensions without SA treatment were used as the negative control, and the suspensions treated with $70 \%$ isopropanol were used as the positive control.

\subsection{TEM}

Logarithmic phase S. aureus cells were treated with SA at $1 \times \mathrm{MIC}$ at $37^{\circ} \mathrm{C}$ for $12 \mathrm{~h}$. The bacterial pellets were then treated as previously reported [15]. The thin sections were observed by TEM (H-600IV, Hitachi, Tokyo, Japan).

\subsection{Membrane Fluidity Assay}

Membrane fluidity can be examined by detecting fluorescence polarization of 1,6-diphenyl1,3,5-hexatriene (DPH; Sigma-Aldrich, St. Louis, MO, USA). The assay was carried out as previously 
reported with minor modifications [27]. Briefly, logarithmic phase $S$. aureus cells were washed twice and re-suspended at a final density of $1 \times 10^{9} \mathrm{CFU} / \mathrm{mL}$ in $0.85 \%$ saline solution. Cell suspensions were incubated with three different concentrations of SA $(1 / 8 \times \mathrm{MIC}, 1 / 4 \times \mathrm{MIC}, 1 / 2 \times \mathrm{MIC})$ at room temperature for $1 \mathrm{~h}$. After DPH was added to the above solution to reach a final concentration of $10^{-6} \mathrm{M}$, the suspensions were incubated for $30 \mathrm{~min}$ at room temperature again. Fluorescence polarization was measured by a microplate reader (Synergy H1, BioTek, Winooski, VT, USA). The fluorescence excitation and fluorescence emission were $360 \pm 40 \mathrm{~nm}$ and $460 \pm 40 \mathrm{~nm}$. The fluorescence polarization $(p)$ value is calculated by the following formula [32]:

$$
p=\left(I_{\mathrm{VV}}-G I_{\mathrm{VH}}\right) /\left(I_{\mathrm{VV}}+G I_{\mathrm{VH}}\right)
$$

where $I_{\mathrm{VV}}$ is the vertical excitation fluorescence intensity and $I_{\mathrm{VH}}$ is the horizontal excitation fluorescence intensity, when the fluorescence excitation is in the vertical direction. The $G$ is expressed as a corrected factor.

\subsection{Effect of SA on S. aureus Membrane Protein}

The effect of SA on membrane protein of $S$. aureus was determined by the reported method with minor modifications [27]. Logarithmic phase S. aureus cells were washed twice and re-suspended to make the concentration of $1 \times 10^{10} \mathrm{CFU} / \mathrm{mL}$ in $0.85 \%$ saline solution. An amount of $0.3 \mathrm{~mL}$ of bacterial suspensions was added to $2.7 \mathrm{~mL}$ of KI or SA solution with different concentrations. After incubation for $1 \mathrm{~h}$ at room temperature, the fluorescence was measured using a fluorescence spectrophotometer (G9800A, Agilent). The emission spectra of this experiment were scanned from 280 to $400 \mathrm{~nm}$, and the excitation wavelength was set at 258 or $296 \mathrm{~nm}$.

\subsection{Statistical Analysis}

All experiments in this study were performed in triplicate. Statistical analyses were carried out by the SPSS software (version 20.0; SPSS, I., Chicago, IL, USA). The data were expressed as the mean values \pm standard deviation $(n=3)$. A probability value at $p<0.05$ was considered statistically significant.

\section{Conclusions}

The antibacterial mechanism of SA to $S$. aureus was investigated by examining membrane permeability, membrane potential, membrane integrity, TEM, membrane fluidity and membrane protein binding assays. Based on the data obtained, it could be concluded that the antimicrobial effect of $S A$ against $S$. aureus is attributed to its action of SA to $S$. aureus cell membrane, which consequently increases $S$. aureus cell membrane permeability and destroys the membrane integrity, eventually inducing growth inhibition and bacterial death. A significant change of membrane fluidity of $S$. aureus treated with SA was observed, indicating the action of SA to S. aureus is due to the interaction of SA with the bacteria membrane lipids. Results further demonstrated that the antibacterial activity of SA against $S$. aureus could be caused by the interactions of SA with membrane proteins. In general, the bactericidal mechanism involves damaging the cell membrane and other cellular components. Our study provides a novel insight for studying the antimicrobial action of SA to S. aureus and using SA as a potential alternative food preservative in food industry.

Acknowledgments: We thank Isomaro Yamaguchi for valuable advice on the English language and style of this paper. This work was financially supported by the program for new century excellent talents in university. (NCET-10-0591), Sichuan Youth Sci-tech Fund (2012JQ0019), and National Nature Science Foundation of China (31571936).

Author Contributions: Jinrong Bai performed the experiments, collected the test materials and strains. Jinrong Bai wrote the paper and designed the project. Kai Zhong, Hong Gao and Yina Huang analyzed the results and revised the paper. Yanping Wu helped in the experiments. All authors discussed the results and commented on the manuscript. 
Conflicts of Interest: The authors declare no conflict of interest.

\section{References}

1. Le-Loir, Y.; Baron, F.; Gautier, M. Staphylococcus aureus and food poisoning. Genet. Mol. Res. 2003, 2, 63-76. [PubMed]

2. Braden, C.R.; Tauxe, R.V. Emerging trends in foodborne diseases. Infect. Dis. Clin. N. Am. 2013, 27, 517-533. [CrossRef] [PubMed]

3. Elaine, S.; Robert, M.H.; Frederick, J.A.; Robert, V.T.; Marc-Alain, W.; Sharon, L.R.; Jeffery, L.J.; Patricia, M.G. Foodborne illness acquired in the United States-Major pathogens. Emerg. Infect. Dis. J. 2011, 17, 7-15.

4. Kadariya, J.; Smith, T.C.; Thapaliya, D. Staphylococcus aureus and staphylococcal food-borne disease: An ongoing challenge in public health. BioMed Res. Int. 2014, 2014. [CrossRef] [PubMed]

5. Rozemeijer, W.; Fink, P.; Rojas, E.; Jones, C.H.; Pavliakova, D.; Giardina, P.; Murphy, E.; Liberator, P.; Jiang, Q.; Girgenti, D.; et al. Evaluation of approaches to monitor Staphylococcus aureus virulence factor expression during human disease. PLoS ONE 2015, 10, e0116945. [CrossRef] [PubMed]

6. Gustafson, J.E.; Muthaiyan, A.; Dupre, J.M.; Ricke, S.C. Staphylococcus aureus and understanding the factors that impact enterotoxin production in foods: A review. Food Control 2014, 2015, 1-14. [CrossRef]

7. Michailidis, P.A.; Krokida, M.K. Drying and dehydration processes in food preservation and processing. In Conventional and Advanced Food Processing Technologies; Bhattacharya, S., Ed.; John Wiley \& Sons, Ltd.: Hoboken, NJ, USA, 2014; pp. 1-32.

8. Calo, J.R.; Crandall, P.G.; O’Bryan, C.A.; Ricke, S.C. Essential oils as antimicrobials in food systems-A review. Food Control 2015, 54, 111-119. [CrossRef]

9. Tripathi, P.; Rawat, G.; Yadav, S.; Saxena, R.K. Shikimic acid, a base compound for the formulation of swine/avian flu drug: Statistical optimization, fed-batch and scale up studies along with its application as an antibacterial agent. Antonie Van Leeuwenhoek 2015, 107, 419-431. [CrossRef] [PubMed]

10. Just, J.; Deans, B.J.; Olivier, W.J.; Paull, B.; Bissember, A.C.; Smith, J.A. New method for the rapid extraction of natural products: Efficient isolation of shikimic acid from star anise. Org. Lett. 2015, 17, 2428-2430. [CrossRef] [PubMed]

11. Chen, F.; Hou, K.; Li, S.; Zu, Y.; Yang, L. Extraction and chromatographic determination of shikimic acid in chinese conifer needles with 1-benzyl-3-methylimidazolium bromide ionic liquid aqueous solutions. J. Anal. Methods Chem. 2014, 2014. [CrossRef] [PubMed]

12. Rabelo, T.; Zeidán-Chuliá, F.; Caregnato, F.; Schnorr, C.; Gasparotto, J.; Serafini, M.; de Souza-Araújo, A.; Quintans-Junior, L.; Moreira, J.; Gelain, D. In vitro neuroprotective effect of shikimic acid against hydrogen peroxide-induced oxidative stress. J. Mol. Neurosci. 2015, 56, 956-965. [CrossRef] [PubMed]

13. Tang, L.; Xiang, H.; Sun, Y.; Qiu, L.; Chen, D.; Deng, C.; Chen, W. Monopalmityloxy shikimic acid: Enzymatic synthesis and anticoagulation activity evaluation. Appl. Biochem. Biotechnol. 2009, 158, 408-415. [CrossRef] [PubMed]

14. Xing, J.; Sun, J.; You, H.; Lv, J.; Sun, J.; Dong, Y. Anti-inflammatory effect of 3,4-oxo-isopropylidene-shikimic acid on acetic acid-induced colitis in rats. Inflammation 2012, 35, 1872-1879. [CrossRef] [PubMed]

15. Zeng, W.C.; He, Q.; Sun, Q.; Zhong, K.; Gao, H. Antibacterial activity of water-soluble extract from pine needles of Cedrus deodara. Int. J. Food Microbiol. 2012, 153, 78-84. [CrossRef] [PubMed]

16. Sila, A.; Hedhili, K.; Przybylski, R.; Ellouz-Chaabouni, S.; Dhulster, P.; Bougatef, A.; Nedjar-Arroume, N. Antibacterial activity of new peptides from barbel protein hydrolysates and mode of action via a membrane damage mechanism against Listeria monocytogenes. J. Funct. Foods 2014, 11, 322-329. [CrossRef]

17. Lou, Z.; Wang, H.; Rao, S.; Sun, J.; Ma, C.; Li, J. p-Coumaric acid kills bacteria through dual damage mechanisms. Food Control 2012, 25, 550-554. [CrossRef]

18. Lacombe, A.; McGivney, C.; Tadepalli, S.; Sun, X.; Wu, V.C. The effect of American cranberry (Vaccinium macrocarpon) constituents on the growth inhibition, membrane integrity, and injury of Escherichia coli O157:H7 and Listeria monocytogenes in comparison to Lactobacillus rhamnosus. Food Microbiol. 2013, 34, 352-359. [CrossRef] [PubMed]

19. Li, G.; Wang, X.; Xu, Y.; Zhang, B.; Xia, X. Antimicrobial effect and mode of action of chlorogenic acid on Staphylococcus aureus. Eur. Food Res. Technol. 2014, 238, 589-596. [CrossRef] 
20. Lou, Z.; Wang, H.; Zhu, S.; Ma, C.; Wang, Z. Antibacterial activity and mechanism of action of chlorogenic acid. J. Food Sci. 2011, 76, M398-M403. [CrossRef] [PubMed]

21. Berney, M.; Hammes, F.; Bosshard, F.; Weilenmann, H.-U.; Egli, T. Assessment and interpretation of bacterial viability by using the LIVE/DEAD baclight kit in combination with flow cytometry. Appl. Environ. Microbiol. 2007, 73, 3283-3290. [CrossRef] [PubMed]

22. Stocks, S.M. Mechanism and use of the commercially available viability stain, BacLight. Cytom. Part A 2004, 61A, 189-195. [CrossRef] [PubMed]

23. Otto, C.C.; Cunningham, T.M.; Hansen, M.R.; Haydel, S.E. Effects of antibacterial mineral leachates on the cellular ultrastructure, morphology, and membrane integrity of Escherichia coli and methicillin-resistant Staphylococcus aureus. Ann. Clin. Microbiol. Antimicrob. 2010, 9, 26-38. [CrossRef] [PubMed]

24. Ulrih, N.P.; Maričić, M.; Ota, A.; Šentjurc, M.; Abram, V. Kaempferol and quercetin interactions with model lipid membranes. Food Res. Int. 2015, 71, 146-154. [CrossRef]

25. Vincent, M.; England, L.S.; Trevors, J.T. Cytoplasmic membrane polarization in Gram-positive and Gram-negative bacteria grown in the absence and presence of tetracycline. Biochim. Biophys. Acta Gen. Subj. 2004, 1672, 131-134. [CrossRef] [PubMed]

26. Qiu, S.; Huang, X.; Xu, S.; Ma, F. The antibacterial activity of ceramsite coated by silver nanoparticles in micropore. Appl. Biochem. Biotechnol. 2015, 176, 267-276. [CrossRef] [PubMed]

27. Ye, X.; Li, X.; Yuan, L.; Ge, L.; Zhang, B.; Zhou, S. Interaction of houttuyfonate homologues with the cell membrane of Gram-positive and Gram-negative bacteria. Colloids Surf. Physicochem. Eng. Asp. 2007, 301, 412-418. [CrossRef]

28. Xing, K.; Chen, X.G.; Liu, C.S.; Cha, D.S.; Park, H.J. Oleoyl-chitosan nanoparticles inhibits Escherichia coli and Staphylococcus aureus by damaging the cell membrane and putative binding to extracellular or intracellular targets. Int. J. Food Microbiol. 2009, 132, 127-133. [CrossRef] [PubMed]

29. Hao, G.; Shi, Y.H.; Tang, Y.L.; Le, G.W. The membrane action mechanism of analogs of the antimicrobial peptide Buforin 2. Peptides 2009, 30, 1421-1427. [CrossRef] [PubMed]

30. Wang, D.; Zhang, W.; Wang, T.; Li, N.; Mu, H.; Zhang, J.; Duan, J. Unveiling the mode of action of two antibacterial tanshinone derivatives. Int. J. Mol. Sci. 2015, 16, 17668-17681. [CrossRef] [PubMed]

31. Sánchez, E.; García, S.; Heredia, N. Extracts of edible and medicinal plants damage membranes of Vibrio cholerae. Appl. Environ. Microbiol. 2010, 76, 6888-6894. [CrossRef] [PubMed]

32. Mei, L.; Lu, Z.; Zhang, X.; Li, C.; Jia, Y. Polymer-Ag nanocomposites with enhanced antimicrobial activity against bacterial infection. ACS Appl. Mater. Interfaces 2014, 6, 15813-15821. [CrossRef] [PubMed]

(C) 2015 by the authors; licensee MDPI, Basel, Switzerland. This article is an open access article distributed under the terms and conditions of the Creative Commons by Attribution (CC-BY) license (http://creativecommons.org/licenses/by/4.0/). 